\title{
Support of Helicopter "Free-Flight" Operations in the 1996 Olympics
}

James R. Branstetter

Federal Aviation Administration

Eric G. Cooper

NASA

October 21-24, 1996

\section{(a) The Engineering Society For Advancing Mobility Land Sea Air and Space I NTERNATIONAL}

SAE International 400 Commonwealth Drive Warrendale, PA 15096-0001 U.S.A.

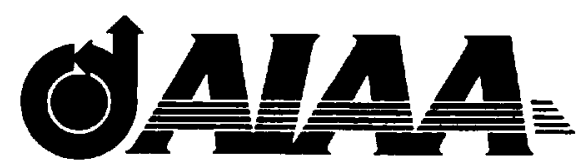

American Institute of Aeronautics and Astronautics 370 L'Enfant Promenade, S.W. Washington, D.C. 20024

For permission to copy or republish, contact the American Institute of Aeronautics and Astronautics or SAE International. 
Published by the American Institute of Aeronautics and Astronautics (ALAA) at 1801 Alexander Bell Drive, Suite 500, Reston, VA 22091 U.S.A., and the Society of Automotive Engineers (SAE) at 400 Commonwealth Drive, Warrendale,PA 15096 U.S.A.

Produced in the U.S.A. Non-U.S. purchasers are responsible for payment of any taxes required by their governments.

Reproduction of copies beyond that permitted by Sections 107 and 108 of the U.S. Copyright Law without the permission of the copyright owner is unlawful. The appearance of the ISSN code at the bottom of this page indicates SAE's and ALAA's consent that copies of the paper may be made for personal or internal use of specific clients, on condition that the copier pay the per-copy fee through the Copyright Clearance Center, Inc., 222 Rosewood Drive, Danvers, MA 01923. This consent does not extend to other kinds of copying such as copying for general distribution, advertising or promotional purposes, creating new collective works, or for resale. Permission requests for these kinds of copying should be addressed to ALAA Aeroplus Access, 4th Floor, 85 John Street, New York, NY 10038 or to the SAE Publications Group, 400 Commonwealth Drive, Warrendale, PA 15096. Users should reference the title of this conference when reporting copying to the Copyright Clearance Center.

ISSN\#0148-7191

This paper is declared a work of the U.S. Government and is not subject to copyright protection in the United States.

All AIAA papers are abstracted and indexed in International Aerospace Abstracts and Aerospace Database.

All SAE papers, standards and selected books are abstracted and indexed in the Global Mobility Database.

Copies of this paper may be purchased from:

AIAA's document delivery service

Aeroplus Dispatch

1722 Gilbreth Road

Burlingame, California 94010-1305

Phone: (800) 662-2376 or (415) 259-6011

Fax:(415) 259-6047

or from:

SAExpress Global Document Service

c/oSAE Customer Sales and Satisfaction

400 Commonwealth Drive

Warrendale, PA 15096

Phone: (412)776-4970

Fax: (412)776-0790

SAE routinely stocks printed papers for a period of three years following date of publication. Quantity reprint rates are available.

No part of this publication may be reproduced in any form, in an electronic retrieval system or otherwise, without the prior written permission of the publishers.

Positions and opinions advanced in this paper are those of the author(s) and not necessarily those of SAE or AIAA. The author is solely responsible for the content of the paper. A process is available by which discussions will be printed with the paper if it is published in SAE Transactions. 


\title{
965632
}

\section{Support of Helicopter "Free-Flight" Operations in the 1996 Olympics}

\author{
James R. Branstetter* \\ Federal Aviation Administration \\ Eric G. Coopert \\ National Aeronautics \& Space Administration
}

\begin{abstract}
"Operation Heli-STAR" (Helicopter Short-haul Transportation and Aviation Research)
\end{abstract}

\section{"An Olympic Moment"}

The microcosm of activity surrounding the 1996 Olympic Games provided researchers an opportunity for demonstrating state-of-the art technology in the first large-scale deployment of a prototype digital communication/ navigation/ surveillance system in a confined environment. At the same time it provided an ideal opportunity for transportation officials to showcase the merits of an integrated transportation system in meeting the operational needs to transport time sensitive goods and provide public safety services under a real-world conditions.

Five aeronautical CNS functions using a digital datalink system were chosen for operational flight testing onboard 91 aircraft, most of them helicopters, participating in the Atlanta Short-Haul Transportation System. These included: GPS-based Automatic Dependent Surveillance, Cockpit Display of Traffic Information, Controller-Pilot Communications, Graphical Weather Information (uplink), and Automated Electronic Pilot Reporting (downlink).

Atlanta provided the first opportunity to demonstrate, in an actual operating environment, key datalink functions which would enhance flight safety and situational awareness for the pilot and supplement conventional air traffic control. The knowledge gained from such a large-scale deployment will help system designers in development of a national infrastructure where aircraft would have the ability to navigate autonomously.
Introduction

In advance of the 1996 Olympic Games in Atlanta, city transportation officials and local businesses recognized the need for an effective infrastructure to move time critical goods and provide essential safety services for citizens and the multitude of visitors expected to descend on the city during the Games. At the same time, Olympic officials had a need to provide security for athletes in and around the Olympic Village and surrounding game venues. From the air, the surface traffic pattern for the Atlanta metro area looks like a spider's web with traffic from three major interstate highways as well as the plethora of local connector roads converging at a central downtown hub (see Figure 1). Coincidentally, the majority of Olympic venues were located downtown near the confluence of traffic flowing from major arteries. Atlanta traffic, under normal conditions, can best be described as hectic at all hours of the day without the need to accommodate the added multitudes descending on the city to attend the Games.

Two years in advance of the Games coming to Atlanta, a group known as the Atlanta Vertical Flight Association (AVFA) was created by concerned local businesses. This group included: Federal Express, the United States Parcel Service, Nations Bank, the Atlanta-Journal Constitution, Cable Network News, Coca-Cola, the Southern Company, Channel 11 News and Delta Airlines in consultation with Helicopter Association International. The group's objective was to jointly pioneer a multimode transportation system that would meet the immediate needs of the Olympics and provide a lasting infrastructure for a city which heretofore had very little in the way of vertical flight operations. From this nucleus, a consortium was formed including the Aviation Security Operations Committee 
(ASOC) the key aviation element holding combined security interests within the Atlanta Committee for Olympic Games (ACOG), the Georgia Emergency Management Agency (GEMA), Georgia Baptist Hospital, Erlanger Medical Center, the Georgia State Patrol, the Georgia National Guard and local police departments. The consortium was rounded out by participation of governmental organizations including the Federal Aviation Administration, National Aeronautics and Space Administration and the Federal Emergency Management Agency. Georgia Tech Research Institute (GTRI) provided support for the cargo-hauling operation with helicopter and heliport logistics and noise monitoring. Systems Applications International Corp. (SAIC) provided support for flight operations.

These combined entities pooled their resources and became known as the Atlanta Short-Haul Transportation System, or ASTS. Shortly before the games began it was decided that a tactical name was needed to assist two-way radio communications between the helicopters and the ground monitoring centers; hence the salutation "Operation Heli-STAR" was contrived (HELIcopter - Short-haul Transport And Research) as nearly all flight operations involved helicopters. This tactical radio call has remained a descriptor for the ASTS operations.

Plans were made by ASTS for deployment of a network of nine new heliports at strategic downtown and suburban locations and improvements to existing facilities at the four primary Atlanta airfields. An interconnecting route structure was established linking the landing zones. From the start, officials were cognizant of the community's possible reaction to the noise generated by a bevy of helicopters flying over a city unaccustomed to any significant level of flight activity. To counteract complaints, helicopter traffic routes were designed to follow interstate highways where possible and approaches to new heliports were situated over industrial or unpopulated areas to the greatest extent. Also, detailed operating criteria were developed with regard for flight safety procedures and consideration for noise concerns in the surrounding neighborhoods.

It quickly became apparent that a communications, navigation and surveillance (CNS) system was needed to communicate with the aircrew and to provide a capability to monitor the location of the helicopters while carrying out their missions. Such capability was especially needed by dispatchers and pilots for those helicopters in the package delivery service operating into the newly deployed heliports. Most of these new land- ing zones were capable of accommodating only a single helicopter on the pad and had no ancillary parking space. Similarly, security officials desired the capability to monitor the location of all participating aircraft operating in and around the Olympic venues, in order to effectively carry out coordination activities in the event of any threat to disrupt the games. With limited technical resources capable of handling the special needs of this project, the ASTS consortium tapped the expertise of another newly formed consortium - the Advanced General Aviation Transport Experiments (AGATE) Alliance - of which the FAA was a member. The needed expertise would come from resources within AGATE's membership of over 160 participants representing industry, government and academia.

The AGATE Alliance was established in April 1995 with the objective of revitalizing the U.S. General Aviation industry through development and deployment of advanced technologies leading to a new generation of aircraft that is easy to fly and yet cost effective in meeting the routine transportation needs of personal and business fliers. AGATE's target market was originally foreseen as filling the gap created in the nation's transportation system when production of single-engine propeller airplanes slumped in the early 1980 's, a decline from which the industry has not yet recovered. To meet the challenge, a number of technical "work packages" have been established focusing on technical issues in the areas of:

- Integrated Flight Systems,

- Propulsion/Sensors \& Controls,

- Icing Protection Systems,

- Design \& Manufacturing,

- Training Systems, and

- Air \& Ground Infrastructure.

While AGATE is primarily dedicated to development of single-engine, fixed-wing aircraft, the surrounding infrastructure issues are common to all modes of flight. The AGATE vision for new aircraft development promotes the concept of autonomous flight with smart systems to aid the pilot in the task of flying in near-all-weather conditions. To accomplish this task, technology is being applied in the areas of graphical flight planning, advanced cockpit displays for traffic and weather information, and air traffic control communications via datalink. This philosophy, and application of technology, is consistent with the current movement within the airline industry towards "freeflight". 
By serendipitous coincidence, participants in the Flight Systems Work Package had, within the past year, formed teams focused on providing additional technological development for databus systems, datalink communications, and multifunction displays required to implement the AGATE vision. It was from this body that ASTS requested assistance to provide technical expertise and manpower with which to deploy a CNS system capable of serving the needs associated with the upcoming Olympic Games. After careful consideration as to the merits of participating in the ASTS project, it was by unanimous votes of both the Flight Systems Technical Council and the AGATE Executive Committee that the challenge was undertaken.

The primary AGATE corporate participants were: ARNAV Systems Inc., Harris Corporation, Pan AM Systems, Digital Equipment Corp., AvroTec, Inc., Terra Corp. (now Trimble Navigation), ARINC Inc., NavRadio Corp., Cirrus Design Corp. and SAMA. CNS project oversight and logistical support came from NASA's Langley Research Center and the FAA's Langley Engineering Field Office. Funding for the effort came from the FAA through the Office of General Aviation and Vertical Flight and, except for hardware purchases, government funds were matched with contributions by the AGATE corporate members.

\section{System Design}

The initial requirement identified by the ASTS partners was the need to provide communications, navigation, and surveillance (CNS) services for approximately fifty helicopters to support security and surveillance operations, emergency services, and cargohauling operations for the duration of the Olympics. After surveying the primary ASTS requirements, design of the CNS system was undertaken with the secondary consideration for the technical development nature of the AGATE program and a mutually agreeable set of objectives was developed. The CNS system delivered would be an engineering prototype assembled from commercial off-the-shelf hardware available to the AGATE partners, and integrated into an operable system capable of handling the entire ASTS requirement.

Five primary CNS functions were jointly identified by ASTS and AGATE leaders as necessary to support the wide range of helicopter operations. These consisted of:

- Automatic Dependent Surveillance-Broadcast (ADS-B)
- Cockpit Display of Traffic Information (CDTI)

- Weather Information uplink (WX)

- Controller-Pilot Datalink Communications (CPDLC)

- Automated (Electronic) Pilot Report transmission (EPIREPS)

These functions were given weighted merit during system design deliberations as to their utility for meeting ASTS needs as well as providing technical insight to research issues identified by AGATE partners. The large-scale deployment of aircraft in an operational demonstration, such as surrounded the Olympics, afforded the unique opportunity to exploit the capabilities of this new technology and address issues of concern in the development of a national "free-flight" system.

Important and common to all operations was the requirement for ground personnel to track and monitor the location of participating aircraft as they performed their individual missions. Participating helicopters would be flying in generally unrestricted airspace, as most of the airspace overlying the Olympic Village and downtown venues was outside or below FAA-classified airspace for Atlanta's Hartsfield Airport and classified airspace surrounding the major general aviation airports (Fulton County and Peachtree DeKalb). Complicating the surveillance requirement was the fact that the helicopters would be flying at low altitudes placing them below existing radar coverage from the two nearby air traffic surveillance radars, located at Atlanta Hartsfield Airport (seven miles, south) and Dobbins Air Force Base (10 miles, northwest). Tracking of the helicopters would be needed beginning on the surface and continuing up to approximately 1500 feet for the typical mission profile. Conventional radar only allowed tracking down to approximately 1800-2000 feet over the city and major venues.

To meet this requirement, a broadcast form of automatic dependent surveillance (ADS-B) was employed to transmit position information from the aircraft to the ground monitoring stations. This technique involves an aircraft broadcasting its position, obtained from an independent onboard navigation system, to receivers on the ground via digital datalink. See Figure 2. Global Positioning Satellite (GPS) data was used as the airborne navigation information source. Position coordinates, broadcast from individual aircraft, were subsequently shown on the ground situation displays in graphic form much like a conventional radar screen. 
Inherent in the two-way design of the datalink system, to support air/ground messaging for ADS, was the capability for aircraft, equipped with a companion receiver and graphical display, to implement additional airborne functions. In a manner similar to that used by the ground stations, aircraft equipped with a multifunction display (MFD) were able to receive and display the same position coordinates from the ADS broadcast originating from participating aircraft. Hence it was possible demonstrate the Cockpit Display of Traffic Information (CDTI) feature onboard aircraft that elected to equip with a MFD.

Similarly, the opportunity was provided for the reception and display of weather information for aircraft equipped with a MFD. Nexrad weather radar and airport surface observations were coded by the ground network control station and broadcast to the aircraft on a periodic basis. Approximately every five minutes a new meteorological data set was automatically transmitted for reception by equipped aircraft.

The two-way interactive nature of the system permitted additional testing of several concepts aimed at enhancing Controller-Pilot Datalink Communications (CPDLC). Through the use of keyboards and interactive "touch screen" displays at the ground monitoring stations, operators could send free text or prepared messages to the cockpit. This would allow ground mission managers an alternate means to communicate with aircraft in flight, as two-way radio frequencies were congested.

The final capability to be demonstrated was that of automatically generating Electronic Pilot Reports (EPIREPS) for transmission to the ground or other aircraft. In a manner similar to the way airlines downlink information from air-data computers directly to the National Weather Service, some of the ASTS-equipped aircraft could downlink experimental meteorological data to the network control station. In a more mature application, temperature, dewpoint, winds and icing information could be used by NWS computer models to enhance the accuracy of current forecasts and help pave the way towards shorter term forecasts.

\section{Implementation}

Implementation and deployment of the system was predicated on close cooperation and interaction of the primary industry participants lending their individual expertise to the endeavor. Two operational tests were conducted during system evolution; the first in October 1995 demonstrated that the concept was realizable, and a second in February 1996 involved multiple aircraft to demonstrate all the required ASTS capabilities.

Three ground monitoring stations were deployed to handle the varied ASTS missions. The first, referred to as the Traffic Advisory Center (TAC), was located on Dobbins Air Force Base and used by security officials and air traffic controllers to monitor and track aircraft entering restricted airspace. The TAC (see Figure 3) employed two ADS-B situation displays (for redundancy) which were programmed to show the position of all aircraft with compatible CNS avionics flying within datalink coverage. The 20 -inch color displays showed the position of participating aircraft as small icons annoted with identification tags much like ATC radar, see Figure 4. Each console position was equipped with a keyboard and "touch-screen" interactive display for composing two-way digital datalink messages for transmission to the aircraft (Figure 5).

The second ground monitoring station was located at GTRI, outside the Dobbins gate, and was used for dispatch and monitoring of the helicopters used in the cargo-hauling operation. Referred to as the Project Operations Center (POC), this facility was accessible to persons wanting to observe the system and view nonsecure operations. Traffic shown on the POC displays was filtered to show only non-security flight operations.

A third ground display was installed at GEMA's Emergency Operations Center (EOC) in downtown Atlanta, where the combined emergency response teams were located. This display showed the same full complement of traffic (i.e. secure and non-secure) as the TAC displays.

The POC location was chosen as the primary site for network control and for reception of ADS messages from aircraft because of its higher elevation. From there, aircraft position data was sent over dedicated telephone lines to the TAC which hosted the primary display processor. A backup receiver was installed at the TAC in case of failure of the primary station. Processed data was sent back over phone lines to the POC for display and, similarly, to the EOC at GEMA.

Two ground repeaters were used to extend the coverage range for aircraft flying to outlying venues: one located on the control tower at Atlanta Hartsfield and a second at the Peachtree DeKalb tower. Also, each airborne datalink unit had the capability of being commanded from the ground to act as a repeater, similar to those on the ground, for relay of signals from 
aircraft beyond the reception range of the ground stations. Frequently, one of the blimps operated by the Atlanta Police Department and stationed over the Olympic Village was used as the sole repeater since it had a commanding view of all participating aircraft. This served to reduce the number of messages being repeated over the network allowing for faster update rates during times of peak activity.

The typical aircraft avionics suite (Figure 6) consisted of three pieces of hardware: an integrated GPS receiver and datalink transceiver unit, a solid-state liquid-crystal multifunction display (MFD) and the associated airborne processor. The pilot was able to access various display modes from an on-screen menu, commanded by a series of buttons on each side of the display.

The CDTI mode (Figure 7) allowed the ADS-B function of participating aircraft to be displayed as target icons on the screen with an adjustable scale of approximately 5 to 13 miles in range. A traffic display format was used similar to that implemented by the airlines for Threat Alert and Collision Avoidance Warning System (TCAS). A moving map mode was implemented on the MFD, which had an adjustable range of 75 or 150 miles with the capability of displaying ground obstructions and special use airspace. The graphic weather display (Figure 8) showed Nexrad radar data in block cells.

\section{Operations}

From the onset, security interests of the Atlanta Committee for the Olympic Games pressed for a flight restricted area encompassing all of the city and Olympic venues. The FAA recognized this would place restrictions on a great deal of airspace heretofore designated unrestricted, thereby denying many pilots the right to fly. A compromise was reached whereby airspace would be continuously restricted over the Olympic Village and temporarily restricted over the game venues when they were active. Temporary Flight Restricted (TFRs) areas were charted, and disseminated via special "Notices To Airmen".

Mandatory aircrew training was required prior to operations within the designated TFRs and a special airspace chart was required for navigation. Two sessions of training were established for pilots; the first, conducted by personnel from the FAA's Southern Region Headquarters, was oriented towards operations permitted within the TFRs. The second, conducted by
ASTS personnel, focused on the operation of the CNS equipment and heliport operating procedures. According to detailed procedures established for operating in the flight restricted zones, all participating aircraft would establish voice contact with the Traffic Advisory Center for target identification and ADS monitoring. Those helicopters conducting cargo operations would take further instruction from the Project Operations Center after their initial contact with the TAC.

Several weeks before the opening ceremonies, the White House issued a notice that required all aircraft desiring to fly over any of the Olympic venues to be equipped with CNS avionics. Heretofore, flight within the TFRs did not require such equippage since participation in the ASTS project was voluntary and served mainly to demonstrate a prototype system. The FAA was tasked to provide additional avionics, compatible with the now-deployed CNS system, to aircraft operators who had expressed intent to fly. Federal funds were made available and 60 additional CNS avionics units were built under a letter of national exigency. These units were designed to be portable and included self contained batteries and window mount antennas, capable of being carried onboard different aircraft. The additional units enhanced the research aspects of the exercise by providing the opportunity to track a greater number of aircraft than otherwise would have been possible.

A total of 91 aircraft were equipped with compatible CNS avionics. These included helicopters for the security, law enforcement and emergency services as well as eight helicopters dedicated to the cargo-hauling operation. Three blimps operated by the Atlanta Police Department were included in the total. One of them was usually to be found hovering over the Olympic Village at all hours of the day and night. The CNS unit on this aircraft was often used as an airborne repeater which greatly extended the range over which participating aircraft could be tracked.

Aircraft installations continued up to and during the opening days of the Games as new needs were identified. Aircraft installations consisted of either permanently installed systems with outside mounted antennas, as originally planned for the ASTS demonstration, or portable units typically operating with GPS and datalink antennas placed in the window.

Operations at the Traffic Advisory Center were conducted on a 24-hour basis beginning the week prior to opening ceremonies and concluding two days after 
the close of the Games. The ground situation displays were manned by a team of 10 Air Traffic Control Specialists. These personnel had the primary responsibility for coordinating airspace use with security officials and effecting the orderly conduct of air traffic in and around the TFRs. Much credit is due this highly experienced and dedicated team for maintaining smooth operations throughout the duration of the games.

While two-way radio contact with the TAC was required of all aircraft while operating in the TFRs, the ADS-B situation displays became the primary tool at the controllers disposal to track aircraft. TAC operations were augmented with a "DBRITE" radar display remoted from the Dobbins surveillance radar, showing primary and beacon target traffic down to 1800 feet. However, only the ADS-B system was capable of displaying traffic position information below radar coverage; this included tracking aircraft while on the ground.

The Project Operations Center was manned for two daily shifts by personnel from the FAA and GTRI who provided oversight for all cargo operations. Smooth operation of this mission was critical for an effective demonstration of the ASTS concept to the satisfaction of business partners having to move time critical goods. Cargo operations alone were planned to consume over 1400 hours of flight time and carry 1.5 million pounds of time-sensitive cargo for ASTS participants over the 17 days of the Olympic Games.

Cargo-hauling flights were conducted by a fleet of eight dedicated helicopters based at Peachtree DeKalb airport and operated over specified routes between the newly deployed heliports. The ADS-B situation display at the POC was invaluable for dispatchers monitoring the helicopters in order to maintain delivery schedules. The real-time and recorded data from ADS-B position reports also served to provide timely response to noise complaints from the community, quite often exonerating participating ASTS pilots. Many unrelated helicopter operations were being conducted in and around Atlanta other than those specifically under the purview of ASTS.

\section{Results}

This exercise comprised the largest single demonstration and test of an integrated CNS system to date in the U.S., which incorporated multiple datalink functions (ADS-B, CDTI, CPDLC, and weather up- and downlink). Unlike previous demonstrations conducted by the FAA, this system used a VHF datalink system for datalink communications between the ground system and aircraft. The AGATE partners provided a prototype system that was effectively used by pilots and controllers in the conduct of actual mission operations while serving research interests at the same time.

Notwithstanding the White House mandate at the eleventh hour requiring around the clock operations and that all aircraft entering the flight restricted zones to be CNS equipped, all parties rallied together to pull off an efficient, coordinated operation. The multiple mission aspects of the effort involved the close cooperation of security officials, law enforcement authorities, air traffic control, cargo haulers and the associated logistics and support personnel.

The CNS system was used to support two primary, yet independent, missions throughout the duration of the Olympics. The first, that of providing a means for tracking aircraft flying over and around the Olympic Village and venues, was accomplished to the satisfaction of security interests. The second mission, that of providing cargo-hauling operations with a similar means of tracking and dispatch communications, was accomplished in a likewise successful manner. The ADS-B system allowed helicopters to carry out their individual operations in an expeditious manner without incident.

Since the primary situation displays were designed with advance input from the users, air traffic control specialists found the equipment easy to operate and comprehend. ADS-B was used as the primary means for tracking when aircraft were within datalink coverage. Aircraft could alternatively be monitored via the Dobbins surveillance radar which was remoted to a "DBRITE" display located above the ADS console. However, radar only provided coverage down to an altitude of 1800 feet above the ground and did not incorporate aircraft data tags.

Data tags on the ADS-B traffic display, similar to tags on actual ATC radar displays, aided the controllers in identifying individual aircraft. Tactical call signs were used by controllers for addressing aircraft for positive identification as they became airborne. These call signs were easily added to (or deleted from) the display database for annotating the ADS target icon seen on the display. This was done on a frequent basis as helicopters continued to be added to the operation throughout the duration of the Olympics.

From an overall systems operation perspective, the airborne and ground equipment worked to the satisfac- 
tion of the AGATE designers and users, operating without major glitches once placed in service and throughout the four week period surrounding the Games. The only notable downtimes were attributed to a telephone cable being dug up that carried data from the network control station to the ground display processor at the TAC, and an interruption in service on the same leased telephone circuit. This type of reliability was no small feat for a prototype system. AGATE research personnel and representatives from the equipment providers were available around the clock, either on site or on call, to handle any problems with the ground displays or avionics installations. Fortunately, such problems were few and far between.

The system experience gained by researchers provided a opportunity to study how ADS-B technology could perform in meeting surveillance needs in lieu of ground-based radar. Also, the capability afforded by broadcast-ADS to support "air-to-air" CDTI was of interest, being seen as an important step in the movement towards a "free-flight" operational environment. One of the parameters of key interest with respect to both issues was the timeliness of aircraft position update rates.

Aircraft update rates were initially set to be similar to that of an airport surveillance radar, nominally every five seconds. As viewed on the ground situation displays, update rates were observed to vary over a range from two to thirty seconds, due to varying degrees of data latency. Update rates tended to decrease when more targets were being tracked. Also, transmission of weather datalink messages and the occasional need to effect configuration changes to the ground-based repeater network served to slow update rates, as weather information broadcasts and network control commands were issued on the same frequency as aircraft position reports. The adaptive nature of the transmission scheme in the communication system design allowed the timing of each aircraft's transmission to occur on a non-synchronous basis in order to reduce simultaneous transmissions. Helicopters, dedicated to the cargo-hauling operation, had their position update rate specifically set to transmit every second. This was done to correlate precise aircraft location with data being collected by sound level monitors on the ground. Further analysis of the data should help determine the optimum update rates for various phases of flight.

The solitary complaint reported during ADS-B tracking operations, voiced by the air traffic control specialists and cargo operations monitors, was that of not receiving uniform and continuous position updates from participating aircraft. The algorithms designed into the ground display processor required receipt of a valid position update, from an aircraft, within a thirty second period otherwise the color of the icon on the screen would change from "white" (indicating routine updates) to "red" - indicating aged data and hence an unreliable position. Observations made at the ground operating consoles revealed that most of these problems could be attributed to the reduced ability of aircraft equipped with the portable units to maintain the same signal integrity as compared to that of the permanent aircraft installations.

The initial ASTS helicopters equipped with the AGATE designed CNS hardware had GPS and datalink antennas permanently installed on the outside of the aircraft in optimum positions. Since the portable CNS boxes were mandated at a late date, time did not permit an optimum mounting of the antennas on the exterior. As a result, most of the portable installations had the GPS antenna placed on the glare screen or taped in a window which greatly reduced visibility of the satellites. (GPS requires a minimum of 3 satellites, in view, to render a valid set of position coordinates; with only 12 in the hemisphere, any installation having a limited view of the sky would tend to yield a lower probability of calculating valid and timely aircraft position updates.) Likewise, the datalink antenna was often suboptimally installed in the portable CNS deployments. This antenna was typically affixed with suction cups to a side window thereby reducing the probability of reliably interacting with the primary ground receiver or repeater sites. Loss of timely position reports was especially noticeable when aircraft were flying in areas outside of the triangular layout of ground receivers or with the antenna oriented away from the receiver sites. The combined result of having both antennas internally mounted was a greatly reduced probability of receiving a valid update position within the time window needed to keep the target active on the situation display.

It should be noted that "Differential" GPS was not used for this project, as it was deemed too expensive and time consuming for an event of limited duration. The inaccuracy in vertical position data derived from unaided GPS signals allowed for large discrepancies in the altitude reported by participating aircraft. Hence, an aircraft's indicated altitude, as displayed on the ground situation displays or an aircraft's MFD in the CDTI mode, could be several hundred feet in error. This fact was highlighted as a safety concern in both pilot and controller training sessions. 
Working distances for the ADS-B function were found to be surprisingly good, covering the greater Atlanta area with reliable coverage, aircraft antenna installation notwithstanding. This was illustrated when two fixed-wing aircraft, equipped with complementary CNS avionics, reported ADS-B tracking from a distance of approximately 150 miles while inbound to Atlanta, albeit at a high altitude. Aircraft tracking via ADS-B is theoretically determined to be line of sight from the aircraft to one of the ground repeater/receiver locations.

Aircraft capabilities were greatly enhanced when equipped with the optional multifunction display (MFD). Of approximately 40 permanently installed systems about 25 included the MFD option which permitted viewing of traffic and display of uplinked weather information. The portable CNS boxes were capable of accommodating a MFD (or laptop computer); however, only a couple of operators took advantage of this option. Since helicopters were flying low and on short missions, display of the weather was not a frequently used option as it would have been for aircraft traveling over longer distances and at higher altitudes.

In the air, as with the ground situation displays, the timeliness of position updates for the CDTI function met with variable results and were dependent on reliable, periodic reporting from other aircraft. Also, the update rate associated with the target orientation on the MFD, when the aircraft was executing a turn, was a factor in the pilot's ability to visually acquire traffic in the CDTI mode. This was often due to the fact that MFD had the capability of displaying a number of background options such as waypoints, airports and ground obstructions. With fewer options selected, the display update rate increased and performed reasonably well for indicating traffic.

The raw data transmission rate used for this datalink experiment was $9,600 \mathrm{bps}$, whereas future VHF Datalink (VDL) radios will support data rates up to 31,000 bps. This increase could be used in future applications to enhance update rate and transmission times for weather graphics and similar high-bandwidth products.

Time did not permit rigorous testing of the controller/pilot datalink communications system. Controllers did, however, like the implementation of the touch screen displays for this function. Considerable effort went into the design by FAA air traffic personnel to make it representative of future CPDLC communication systems. The touch screen displays also provided a handy scratchpad to keep a record of active aircraft.

Pilots were asked to fill out questionnaires at the conclusion of each daily mission. These data will be included in the detailed analysis which is currently underway by the FAA. Due to the many facets of this project, and individual teams involved, the myriad of data collected is being analyzed by many different parties. It is expected that this data will be collated and reported upon in detail by the FAA's Office of General Aviation and Vertical Flight early in calendar year 1997.

\section{Future}

One of the immediate benefits of the ASTS operation will be to furnish AGATE researchers, the FAA, and other interested parties with hard data on which to base designs for future deployment of air/ground CNS systems that are cost-effective for general aviation. Creation of an infrastructure and environment, such as used in Atlanta, could lead to free flight operations and translate into aircraft that are easier to fly and able to participate in a cooperative manner with commercial air carrier operations.

AGATE's primary interest is in developing the guidelines, standards and certification methods needed to bring a new generation of aircraft to market. (See Figure 9.) It is important that these aircraft have a lowcost avionics suite that is interoperational with RTCA standards, which heretofore have been primarily designed around air transport needs.

The path to revitalization of the general aviation industry (including similar enhancements for the air carrier fleet) is expected begin by retrofitting the current fleet of aircraft with systems that provide an added margin of safety to flight operations. The first of these will likely be the uplink of graphical weather to the cockpit. In the future, implementation of ADS-B and CDTI will provide pilots improved situational awareness with respect to traffic around them permitting an opportunity for autonomous flight operations. Deployment of datalink technology on a national scale will provide the nucleus for enhanced pilot controller communications in concert with FAA modernization plans.

\section{Summary}

The deployment and demonstration of a prototype digital communications, navigation and surveillance 
system during the 1996 Olympic Games in Atlanta provided the opportunity to support the needs of the Atlanta Short-Haul Transportation System and researchers in the Advanced General Aviation Transport Experiment. The CNS system, installed on 91 aircraft, aided security and emergency management officials in carrying out their mission and provided cargo dispatchers with the means to transport and deliver time-critical goods.

The experience gained throughout the Olympics will go far in benefiting research and development efforts leading to a new generation of cooperative air traffic control techniques and the systems infrastructure necessary in a "free-flight" environment. Although most ASTS operations were flown by helicopters, the analysis and benefits are expected to apply to both general aviation and air carrier aircraft.

This project demonstrated, in a confined environment, the integration of digital datalink functions representative of those needed by the airlines and general aviation. Future research programs will be necessary to make refinements in system design and operational procedures. Additional demonstrations will need to be conducted, on a larger scale and with more rigorous test criteria, in the evolution of a universal system for national deployment.

\section{Author's biographical information}

Jim Branstetter is an aerospace engineer employed by the Federal Aviation Administration since April 1974 and works at the Langley Engineering Field Office. He received the B.S. degree in Electrical Engineering from Ohio University in 1971 and has taken post graduate courses from Monmouth College and George Washington University in electronics and aerospace sciences. He is a commercial, instrument rated pilot and an AIAA Associate Fellow. Mr. Branstetter is providing technical leadership in the area of datalink communications to support the Advanced General Aviation Transport Experiment.

Eric Cooper is a computer engineer employed by the National Aeronautics and Space Administration since May 1989 and works in the Flight Electronics Technology Division at Langley Research Center. He received the B.S. degree in Information Science from Christopher Newport College in 1982 and the M.S. degree in Computer Science from the College of William and Mary in 1988. Mr. Cooper is providing technical leadership in the area of databus development to support the Advanced General Aviation Transport Experiment. 


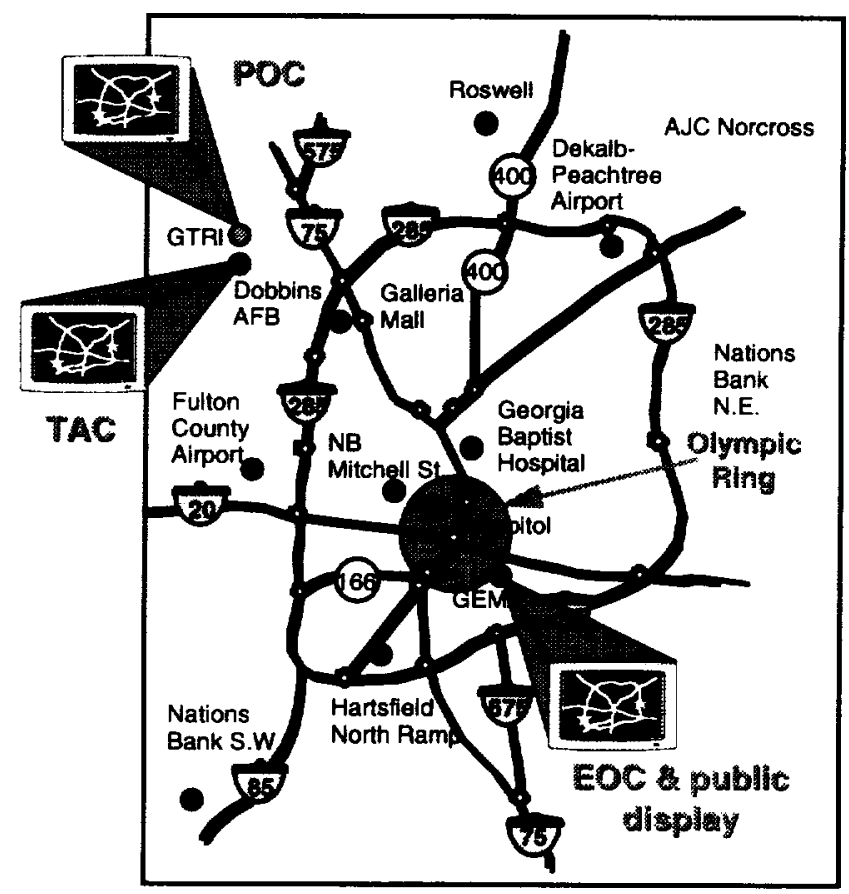

Fig 1. Atlanta metropolitan area - showing airports, heliports, major highways, and ASTS operations centers

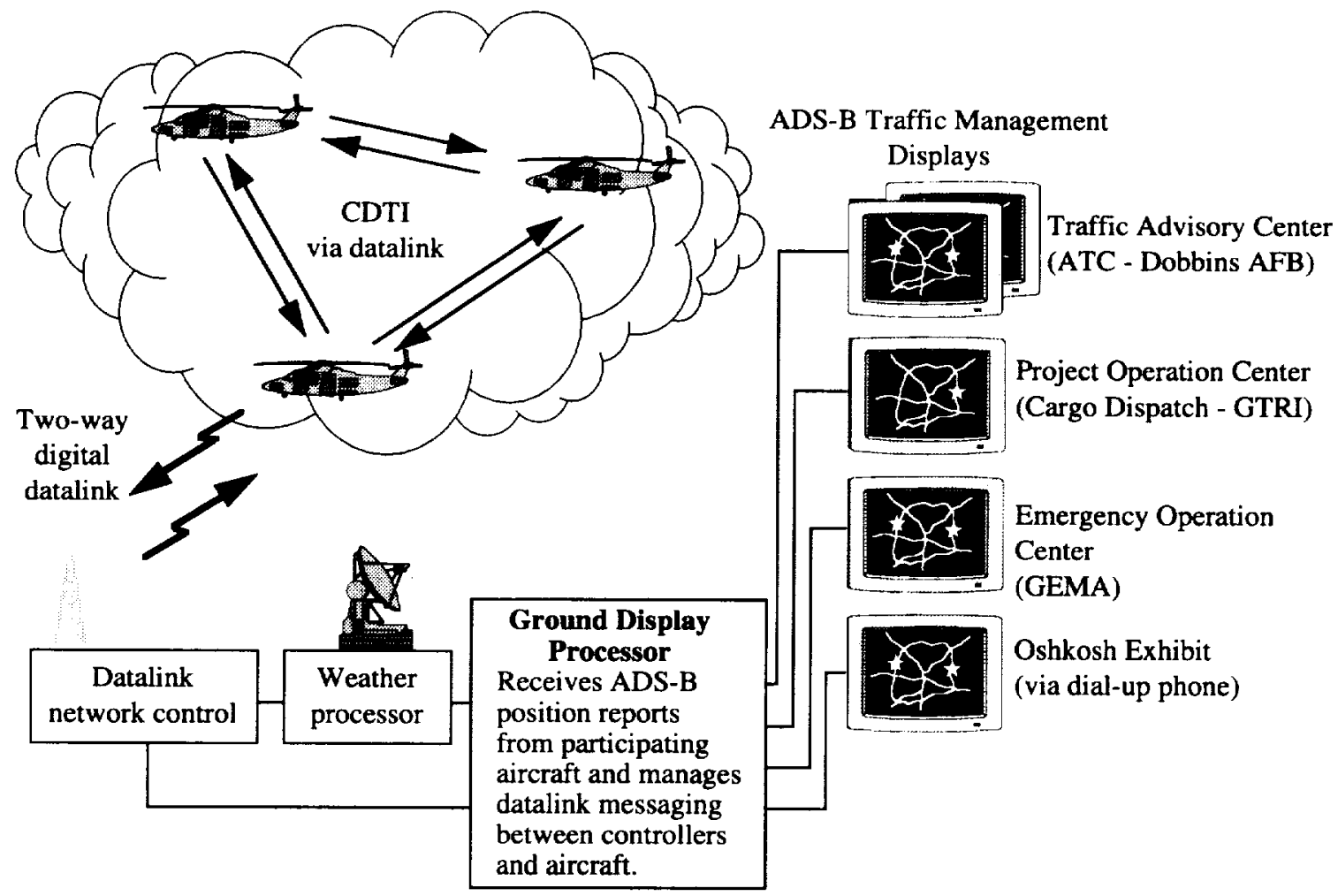

Fig 2. The AGATE partners solution for a communications, navigation, and surveillance system to serve aircraft flying in support of the 1996 Olympic Games 


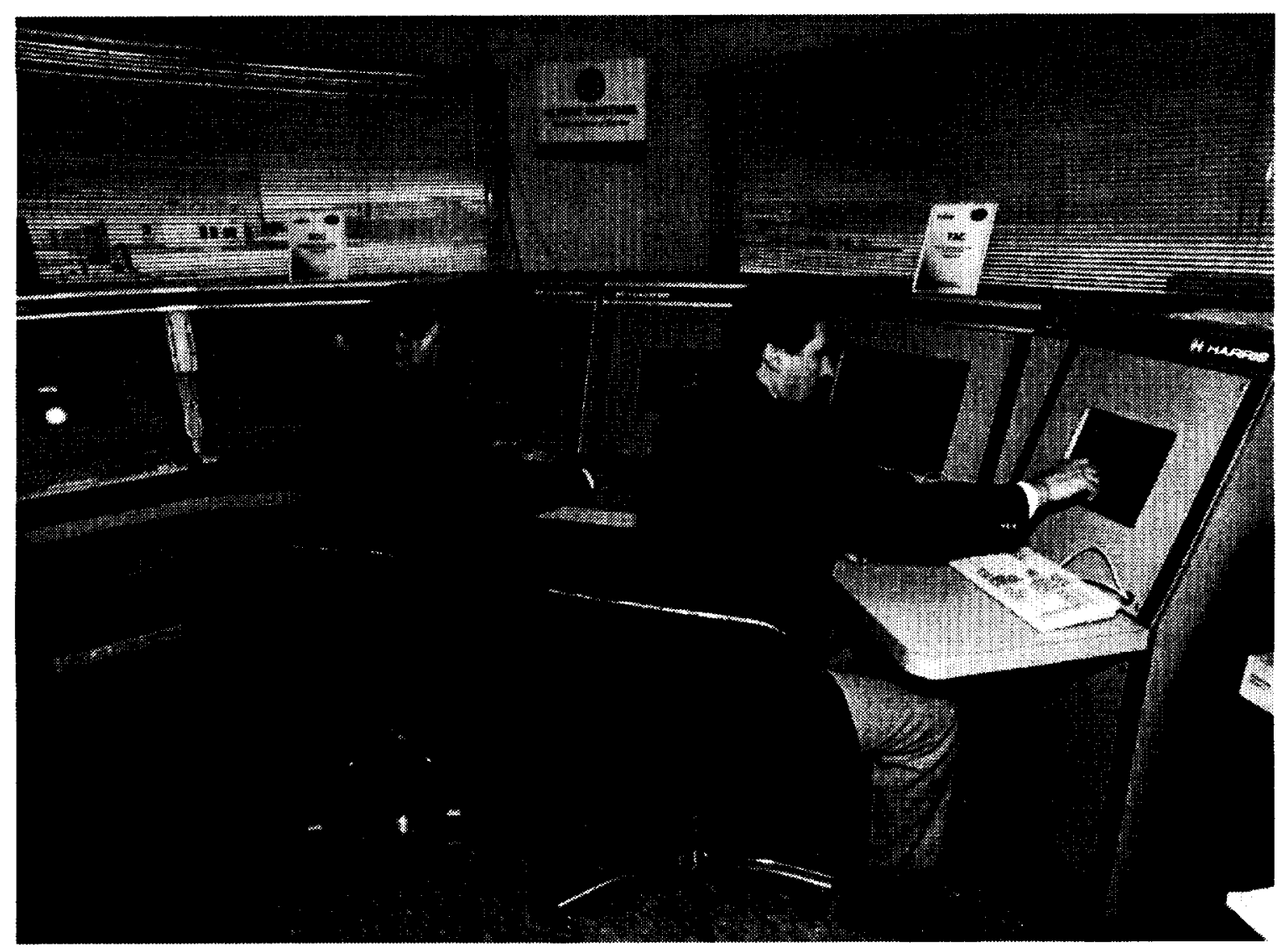

Fig 3. ADS-B ground monitoring system used by air traffic controllers and security personnel at the Traffic Advisory Center, located at Dobbins Air Force Base

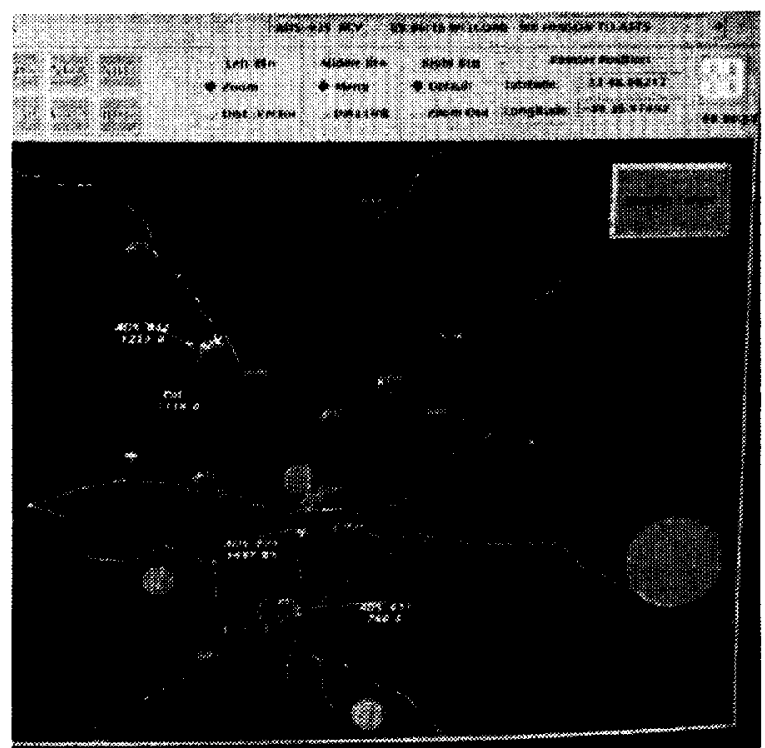

Fig 4. Ground situation display showing ADS-B target aircraft and helicopter route structure around Alanta with Olympic venues marked with circles 


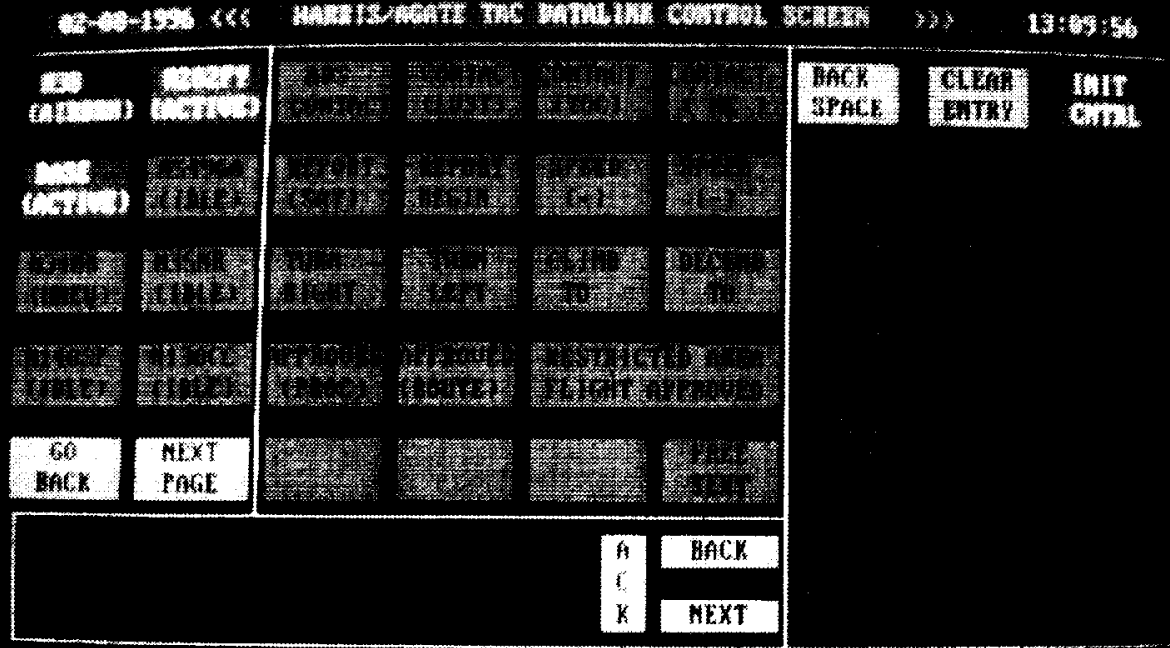

60 of

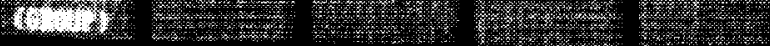

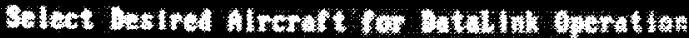

Fig 5. Touch-screen entry device used for voiceless air/ground communications with CNS-equipped aircraft
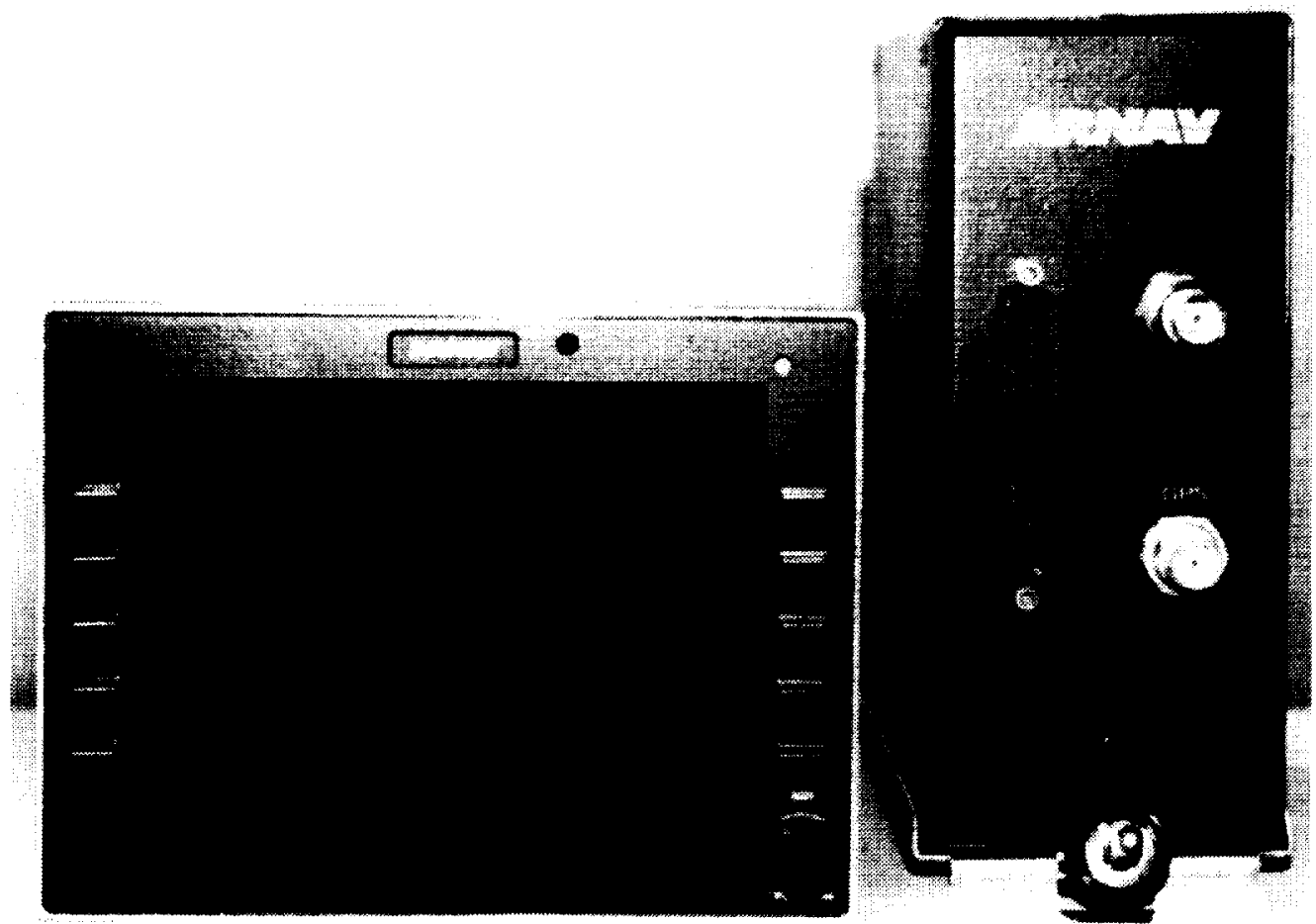

Fig 6. ASTS avionics suite consisting of GPS/datalink unit and multifunction display 


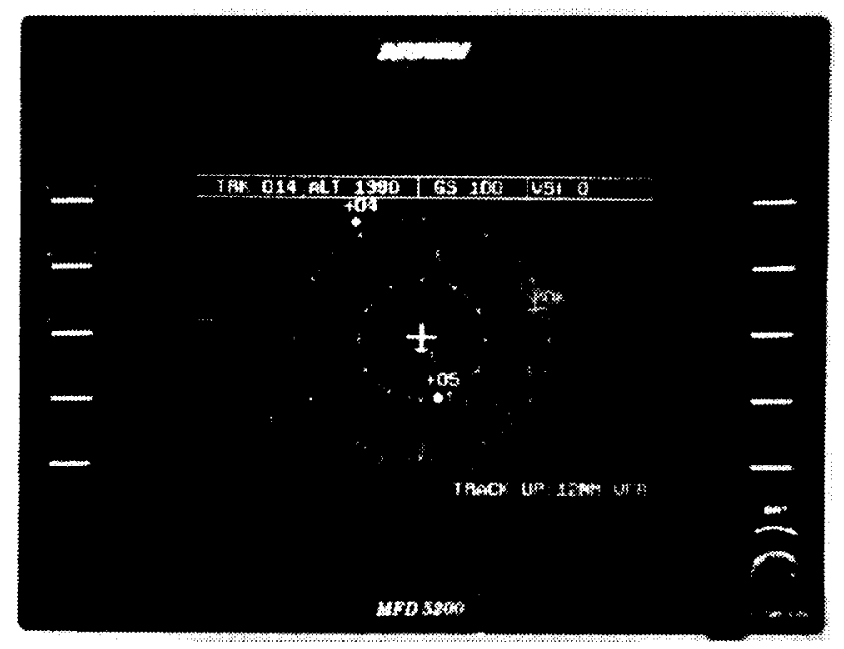

Fig 7. Cockpit Display of Traffic Information enabling pilots to see position of other aircraft, airports, and hazards to navigation

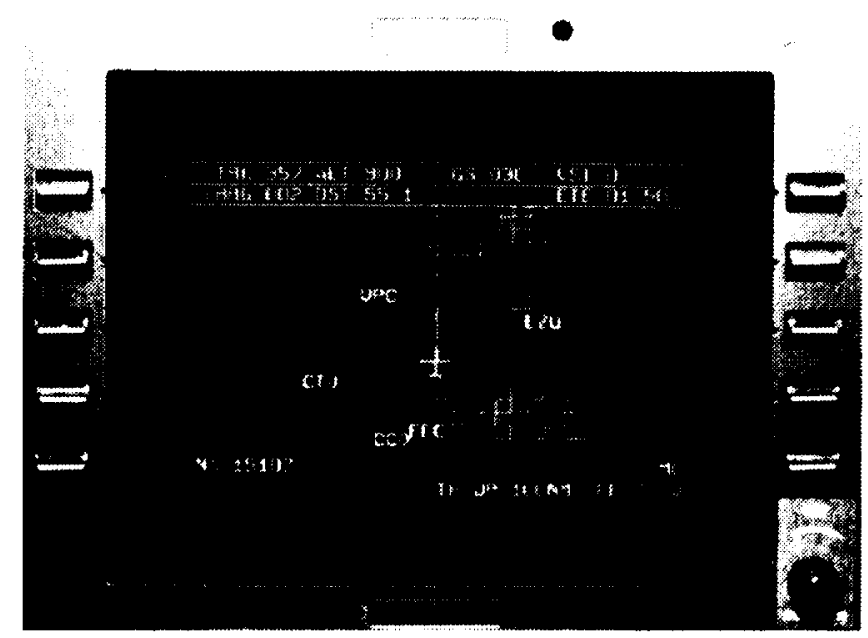

Fig 8. Cockpit display of graphical weather depicting various levels of precipitation

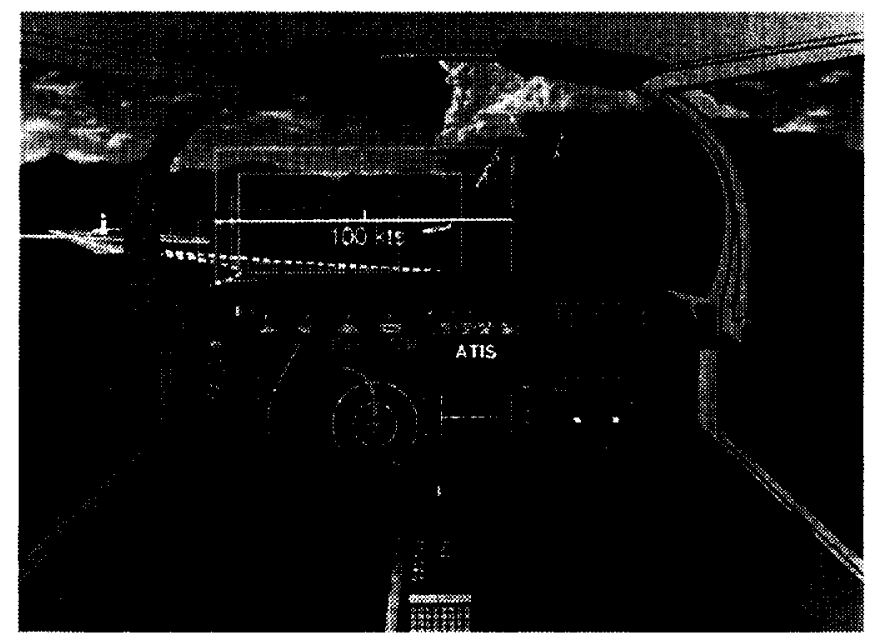

Fig 9. Future cockpit and displays for General Aviation envisioned by AGATE 
